\title{
Selection of stabilizers and processing aids to encapsulate bitter gourd extract in a stable double emulsion
}

\author{
Urmila Choudhary ${ }^{1}$ and Latha Sabikhi ${ }^{2}$
}

Received: 21 June 2020 / Accepted: 25 July 2020 / Published online: 27 October 2020

(c) Indian Dairy Association (India) 2020

\begin{abstract}
The aim of the present investigation was to assess the effect of three formulation variables and their levels on the stability of bitter gourd encapsulated double emulsion using a $3^{3}$ full factorial design. The ingredients used were i) $\mathrm{NaCl}(3-5 \%, \mathrm{w} /$ w), ii) polyglycerol polyricinoleate $(2-4 \%, w / w)$ and iii) protein:polysaccharide complexes (sodium caseinate- $\beta$-pectin / WPC-80- $\beta$-pectin, $1.5-4.5 \%$, w/w). The dependent variables were apparent viscosity, zeta potential, sedimentation stability and turbidity. The optimized formulation consisting of bitter gourd extract $(55.2 \%, \mathrm{w} / \mathrm{w}), 3 \% \mathrm{NaCl}, 4 \%$ PGPR and $4.5 \%$ sodium caseinate-pectin as complex had higher apparent viscosity $(2060 \pm 17.32 \mathrm{cP})$, zeta potential $(-30.33 \pm 0.18 \mathrm{mV})$, lower turbidity $\left(1.18 \pm 0.03 \mathrm{~cm}^{-1}\right)$, and was stable for 29 days at $37^{\circ} \mathrm{C}$, when compared to other combinations $(\mathrm{p}<0.001)$. The study resulted in an optimized emulsion containing bitter gourd extract as a potential delivery vehicle, to incorporate the antidiabetic herbal component in functional foods.
\end{abstract}

Keywords: Dairy protein-polysaccharide complex; NaCl; PGPR; Bitter gourd extract; Stability

\section{Introduction}

Over the past few decades, with increased awareness and interest among consumers in health-enhancing bioactive food components, people have shifted to better alternatives such as

Dairy Technology Division, ICAR-National Dairy Research Institute, Karnal-132 001, Haryana, India

Urmila Choudhary $(\bowtie)$

Dairy Technology Division, ICAR-National Dairy Research Institute

Karnal-132 001, Haryana, India

Email:chaudharyurmila89@gmail.com functional foods over medicine. The quality and quantity of different dietary components are determining factors for overall health. Dietary habits and life style are associated with various metabolic diseases such as diabetes mellitus. Bitter gourd is fast gaining attention as a potential management for diabetes, hence increasing its use in foods and as a dietary supplement (Wu and $\mathrm{Ng}$ 2008; Habicht et al. 2011). Incorporating bitter gourd extract in foods could be a convenient way to combat diabetes mellitus. Utilization of bitter gourd extract needs a medium by which its sensorial aspects can be made acceptable or masked. Double emulsion is one such technique which is used to mask the unacceptable flavor and odor of plant extracts by compartmentalizing it in inner phase, which is then protected by layer of another immiscible liquid. $\mathrm{W}_{1} / \mathrm{O} / \mathrm{W}_{2}$ emulsions can replace conventional $\mathrm{O} / \mathrm{W}$ emulsions, not only by reducing the oil content, but also having similar sensorial perception in mouth (Jiménez-Colmenero 2013; Oppermann et al. 2016). In addition, by way of encapsulation, they can protect heat- and lightsensitive ingredients such as flavor compounds, vitamins and bioactive compounds and facilitate their controlled release within food (Pawlik and Norton 2014).

Instability is the key issue in double emulsion which limit their applicability as food matrices. The type and concentration of surfactants, electrolytes, the nature of encapsulants, ratio of dispersed phase to continuous phase, osmotic balance between inner and outer phase, various processing regimes such as formulation methods, shear applied, temperature of operation and conditions, final desired droplet size and storage conditions are the predominating factors which affect the stability of the double emulsion (Shima et al. 2004). Instability can be reduced by balancing the osmotic pressure between the two aqueous phases (Sameh et al. 2012) and by using protein-polysaccharide electrostatic complexes (Salminen and Weiss 2014) as secondary surfactant. Two different types of surfactants are usually required to stabilize a double emulsion $\left(\mathrm{W}_{1} / \mathrm{O} / \mathrm{W}_{2}\right)$ i.e. primary emulsion surfactant for the inner aqueous droplets and secondary emulsion surfactant for intermediate oil phase droplets. Polyglycerol polyricinoleate (PGPR) is used as an oil-soluble surfactant, which prevents coalescence of newly formed water droplets by the formation of tiny water droplets in the oil phase and facilitates droplet break-up by reducing the interfacial tension (Landfester 
2006; Bahtz et al. 2016). Salt ( $\mathrm{NaCl})$ is an electrolyte that generates the osmotic pressure to counterbalance the Laplace pressure and stabilizes the $\mathrm{W} / \mathrm{O}$ emulsions against Ostwald ripening (diffusional ripening) (Landfester 2006; Capek 2010; Colman et al. 2014). Therefore, the addition of electrolytes along with appropriate hydrophobic emulsifiers and hydrophilic emulsifiers is essential to prepare coalescence-stable $\mathrm{W}_{1} / \mathrm{O} / \mathrm{W}_{2}$ double emulsion.

Biopolymers which includes proteins and polysaccharides may improve the stability of double emulsions by increasing the viscosity of inner and outer water phase of the double emulsion (Surh et al. 2007). Thus, change of particle size is controlled through formation of interfacial layer surrounding droplets (Lutz et al. 2009b; Sameh et al. 2012) and controlling osmotic pressure (Pawlik et al. 2010). Proteins are less effective emulsifiers near their iso-electric $\mathrm{pH}$, which limits their application in acidic foods. Hence, electrostatic protein-polysaccharide complexes gave better functional properties: emulsifying, stability, encapsulation efficiency, texture/rheology, surface hydrophobicity and mouth feel, than that of the proteins and polysaccharides alone even near the iso-electric pH of the protein (Li et al. 2012; HernándezMarín et al. 2013; Klein et al. 2013; Salminen and Weiss 2014). However, the stability of the emulsions stabilized with proteinpolysaccharide complexes is influenced by several factors such as protein-to-polysaccharide molar mass ratio, $\mathrm{pH}$, ionic strength, temperature and processing methods of the complexes (Lutz et al. 2009a,b).

The overall objective of the current investigation was to assess the effect of PGPR, the hydrophobic emulsifier as primary surfactant, $\mathrm{NaCl}$ as an electrolyte and dairy proteinpolysaccharide complexes as secondary surfactant on stability of the bitter gourd extract encapsulated double emulsion $\left(\mathrm{W}_{1} / \mathrm{O} /\right.$ $\mathrm{W}_{2}$ ). The formulated double emulsion was characterized for its physicochemical properties viz., apparent viscosity, zeta potential, sedimentation stability (by visual appearance) and turbidity.

\section{Materials and Methods}

\section{Materials}

PGPR Grinsted ${ }^{\circledR}$ PGPR-90, $\beta$-pectin $[$ GENU® $\beta$-pectin with 18\% degree of acetylation and $>50 \%$ degree of esterification (DE)] were supplied free of cost by $\mathrm{M} / \mathrm{s}$ DuPont Danisco India Pvt. Ltd. (Gurgaon, India) and CP Kelco, Huber India Company (Mumbai, India), respectively. Dairy proteins such as whey protein concentrate- 80 (WPC-80) with $79.86 \%$ protein and $8.09 \%$ lactose and sodium caseinate (SC) with $88 \%$ protein were purchased from M/s Mahaan Proteins Ltd. (New Delhi, India). Aqueous extract of bitter gourd consisting 5.95\% w/w total solids (TS) and 5\% bioactive compound (Charantin) was purchased from M/s Ambe Phytoextracts Pvt. Ltd. (New Delhi, India). Rice bran oil, vinegar (4\% acetic acid) and sodium chloride $(\mathrm{NaCl})$ were purchased from local market of Karnal (India). Reverse osmosis (RO) water was used as an aqueous phase.

\section{Experimental factorial design}

The double emulsion $\left(\mathrm{W}_{1} / \mathrm{O} / \mathrm{W}_{2}\right)$ composed varied concentrations of $\mathrm{NaCl}$ in inner aqueous phase $\left(\mathrm{W}_{1}\right)$ containing bitter gourd extract $(55.2 \%)$, PGPR in middle oil phase $(\mathrm{O})$ and dairy proteinpolysaccharide (WPC-pectin, SC-pectin) complexes (WPC-P/SC$\mathrm{P}, 1: 2)$ in outer aqueous phase $\left(\mathrm{W}_{2}\right)$. All the variables are presented in percentage $(\%), \mathrm{w} / \mathrm{w}$ and their influence on the apparent viscosity, sedimentation stability (at 7 and $37^{\circ} \mathrm{C}$ ) by visual observations, zeta potential and turbidity of the functional mayonnaise were evaluated. The experimental design consisted of 54 formulations (27 each for the two dairy proteinpolysaccharide complexes) as shown in Table 1. A full factorial design approach was adopted to study the influence of the variables and their interaction on the properties of the double emulsion to optimize the double emulsion.

\section{Preparation of dairy protein-polysaccharide complexes}

The formulation of protein-polysaccharide complexes was done according to Salminen and Weiss (2014) with slight modifications. Dairy protein (WPC-80 and SC) and polysaccharide ( $\beta$-Pectin -P) were used in the ratios 1:2 (Kumar et al. 2020). The protein and polysaccharide were weighed into separate beakers for solubilization with RO water according to Table 1. Protein solutions were prepared by magnetic stirring constantly at ambient temperature for 1-2 h, whereas polysaccharide solutions were prepared by magnetic stirring for $6-10 \mathrm{~h}$ at moderate speed to ensure complete dissolution. Protein and polysaccharide solutions were initially adjusted to $\mathrm{pH} 7.0$ using $1.0 \mathrm{~N} \mathrm{NaOH}$ before further mixing. Then, they were mixed together and $\mathrm{pH}$ was reduced up to 4.0 using $4 \%$ acetic acid (vinegar) and stored at ambient temperature for overnight.

\section{Preparation of double emulsion $\left(\mathrm{W}_{1} / \mathrm{O} / \mathrm{W}_{2}\right)$}

Inner aqueous phase $\left(\mathrm{W}_{1}\right)$ was prepared with an aqueous soluble bitter gourd extract, $(55.2 \%, \mathrm{w} / \mathrm{w})$ and varying levels of $\mathrm{NaCl}(3.0-$ $5.0 \%)$ in RO water. Middle oil phase $(\mathrm{O})$ consisted of rice bran oil containing PGPR as hydrophobic emulsifier $(2-4 \%, \mathrm{w} / \mathrm{w})$. Outer aqueous phase $\left(\mathrm{W}_{2}\right)$ was added with either WPC-P or SC-P prepared as explained in the previous section. Both $\mathrm{W}_{1}$ and $\mathrm{O}$ were pasteurized at $72^{\circ} \mathrm{C}$ for $15 \mathrm{sec}$, while outer aqueous phase heated at $85^{\circ} \mathrm{C}$ for $20 \mathrm{~min}$ to prepare biopolymer particles because of thermal denaturation and aggregation of the proteins followed by cooling to $4-7^{\circ} \mathrm{C}$ in ice water bath.

A primary water-in-oil $\left(\mathrm{W}_{1} / \mathrm{O}\right)$ emulsion was premixed by mixing the inner aqueous phase $\left(\mathrm{W}_{1}\right)(30 \%, \mathrm{w} / \mathrm{w})$ with the oil phase $(\mathrm{O})$ $(70 \%, \mathrm{w} / \mathrm{w})$ at room temperature, using a magnetic stirrer at moderate speed for $5 \mathrm{~min}$. The mixture was then homogenized using an Ultra-Turrax [IKA Ultra-Turrax T25 (IKA®) India Pvt. 
Ltd., Bangalore, India] operating at 22,000 rpm for $5 \mathrm{~min}$ to form primary $\mathrm{W}_{1} / \mathrm{O}$ emulsion. The primary $\left(\mathrm{W}_{1} / \mathrm{O}\right)$ emulsion $(30 \%, \mathrm{w} /$ w) was gradually added to the outer aqueous phase $\left(\mathrm{W}_{2}\right)(70 \%$, w/w) and mixed with magnetic stirring at moderate speed for 5 min. The pre-mix was finally homogenized using Ultra-Turrax at $15,000 \mathrm{rpm}$ for $5 \mathrm{~min}$ to produce final double emulsion $\left(\mathrm{W}_{1} / \mathrm{O} / \mathrm{W}_{2}\right)$ $\left(9: 21: 70:: \mathrm{W}_{1} / \mathrm{O} / \mathrm{W}_{2}\right)$.

\section{Apparent viscosity}

A controlled stress rheometer (RHEOPLUS/32 (M/s Anton Paar, $\mathrm{GmbH}$, Ostfildern, Germany), using a cone and plate geometry (CP-75, D $=0.149 \mathrm{~mm}$ ) was used for the measurement of apparent viscosity $(\mathrm{cP})$ in the shear rate range $0.01-100 \mathrm{~s}^{-1}$ at $25^{\circ} \mathrm{C}$ (Lupi et al. 2011).

\section{Zeta potential}

The zeta potential of the double emulsions were measured using Zetasizer Nano-ZS90 (Malvern Instrument Ltd., Malvern, Worcestershire, UK) to determine the stability of the emulsion. The freshly prepared emulsions were diluted 100 times with RO water and the experiment was carried out at $25^{\circ} \mathrm{C}$ temperature. Zeta potential measurements were carried out in triplicate for each emulsion and the results were expressed in $\mathrm{mV}$.

\section{Turbidity}

The turbidity of the double emulsions were determined in triplicates according to Pearce and Kinsella (1978). Aliquots (1 $\mathrm{mL}$ ) of the emulsion were diluted serially with water and sodium dodecyl sulfate (SDS) solution to give final dilutions in the range $1 / 1000$ to $1 / 5000$ and an SDS concentration of $0.170 \%$. The absorbance of the diluted emulsion was then determined in a 1$\mathrm{cm}$ path length cuvette at a wavelength of $500 \mathrm{~nm}$ in a spectrophotometer (M/s Thermofisher Scientific Inc., Rochester, New York, USA). Identical cuvettes were used for all samples and rinsed with a jet of distilled water between determinations. Absorbance of triplicate aliquots of each emulsion was measured in each case.

$\mathrm{T}=\frac{2.303 A}{l}$

where $A$ is the observed absorbance and $l$ is the path length of the cuvette.

\section{Sedimentation stability}

The sedimentation stability (by visual appearance) of the double emulsion was determined in triplicates according to Sapei et al (2012). Freshly made double emulsions were poured into $40 \mathrm{~mL}$ glass vials (internal diameter $=21 \mathrm{~mm}$; length $=90 \mathrm{~cm}$; Corning India, Gurgaon, India) to a height of $46 \mathrm{~cm}$ and stored at $37^{\circ} \mathrm{C}$. The emulsion was observed daily until the phase separation occurred.

\section{Statistical data analysis}

The data obtained were analyzed by two-way analysis of variance (ANOVA) using SPSS (IBM SPSS Statistics 21) software. Significant difference between variables and attributes (apparent viscosity, zeta potential, sedimentation stability and turbidity measurements) of the functional mayonnaise was determined at $p<0.001$. Two-way ANOVA results table of $3^{3}$ full factorial designs are shown in Table 2-5. All experimental attribute measurements were done in triplicate.

\section{Results and Discussion}

Effect of different variables on physicochemical properties of the double emulsion as presented below:

\section{Apparent viscosity}

The effect of $\mathrm{NaCl}(3-5 \%, \mathrm{w} / \mathrm{w}), \mathrm{PGPR}(2-4 \%$, w/w) and two different (WPC-P and SC-P) complexes on the apparent viscosity (at $100 \mathrm{~s}^{-1}$ shear rate) immediately after preparation of the double emulsion $\left(\mathrm{W}_{1} / \mathrm{O} / \mathrm{W}_{2}\right)$ shown in Fig. 1. The double emulsion stabilized with SC-P complex had a very highly significantly $(\mathrm{p}<$ $0.001)$ higher mean value of apparent viscosity than that with WPC-P complex (Table 2). It is clear from Fig. $1(a, b)$ that the apparent viscosity increased $(p<0.001)$ with increase in concentration of both the complexes. Further, as PGPR and $\mathrm{NaCl}$ concentrations increased, apparent viscosity of emulsions stabilized with both complexes (WPC-P and SC-P) increased. The differences in the mean apparent viscosity values were very highly significantly affected by all the variables and their interactions (Table 2).

In the present study, the viscosity of the double emulsions was influenced mainly by relationships between the concentrations

Table $13^{3}$ full factorial designs to investigate the influence of variables on double emulsion

\begin{tabular}{|c|c|c|c|}
\hline \multirow[t]{2}{*}{ Variables $(\%, w / w)$} & \multicolumn{2}{|r|}{ Levels } & \multirow[b]{2}{*}{ High level $(+1)$} \\
\hline & Low level (-1) & Medium level (0) & \\
\hline $\mathrm{NaCl}$ & 3 & 4 & 5 \\
\hline PGPR & 2 & 3 & 4 \\
\hline $\begin{array}{l}\text { Dairy protein-polysaccharide } \\
\text { complexes }(1: 2)\end{array}$ & 1.5 & 3 & 4.5 \\
\hline WPC-P & & & \\
\hline
\end{tabular}


of the protein-polysaccharide complexes and $\mathrm{NaCl}$ in the outer aqueous phase and inner aqueous phase, respectively, and the degree of mobility of the water in the external aqueous phase.
The effect of concentration of the protein-polysaccharide complexes on the apparent viscosity of the double emulsions $\left(\mathrm{W}_{1} / \mathrm{O} / \mathrm{W}_{2}\right)$ was the same as observed by Lutz et al. (2009a).

Table 2 Analysis of variance of apparent viscosity, zeta-potential and turbidity of double emulsion stabilized with WPC/SC-P complex at $37^{\circ} \mathrm{C}$

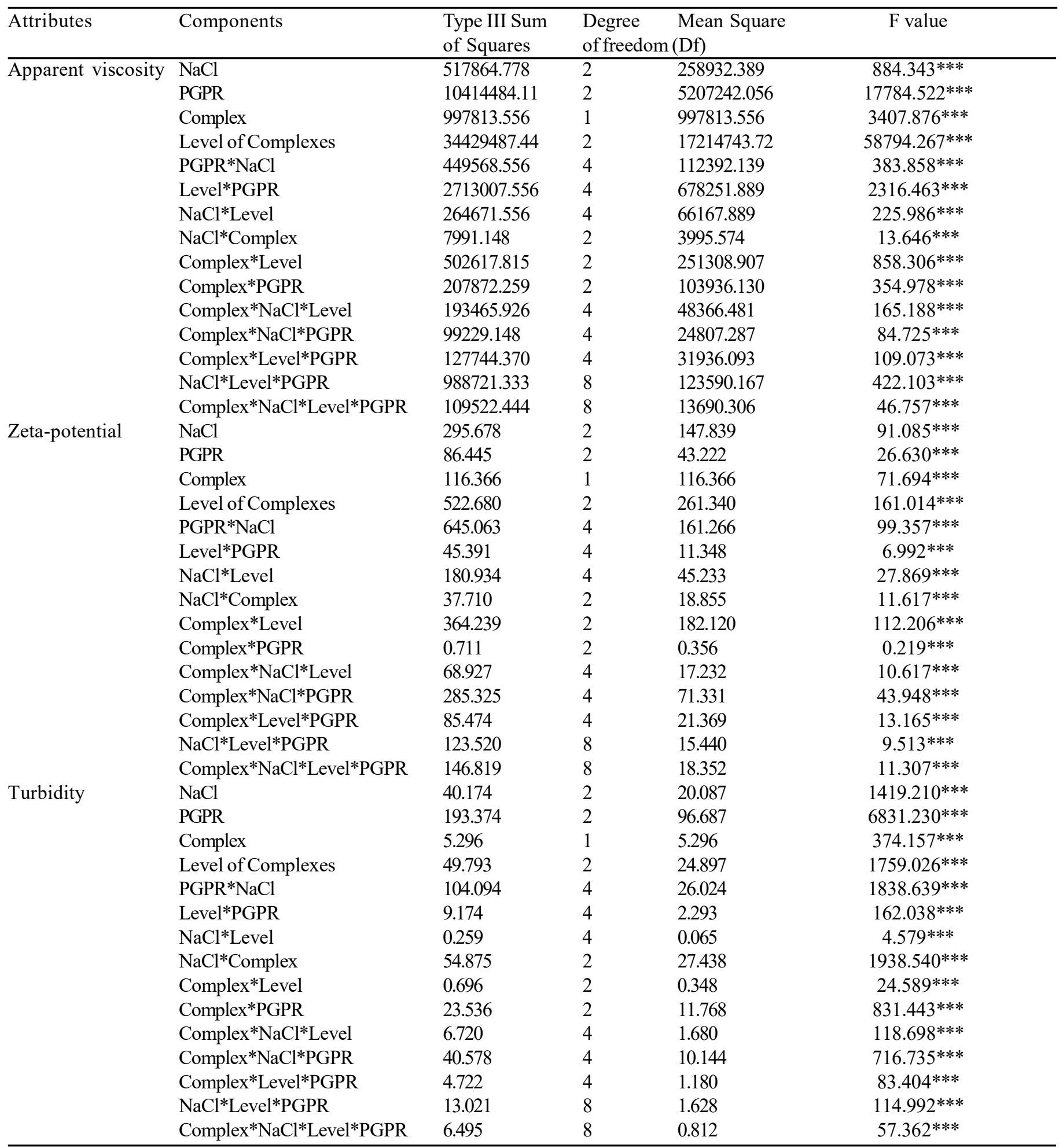

***Significant at $\mathrm{p}<0.001$ 


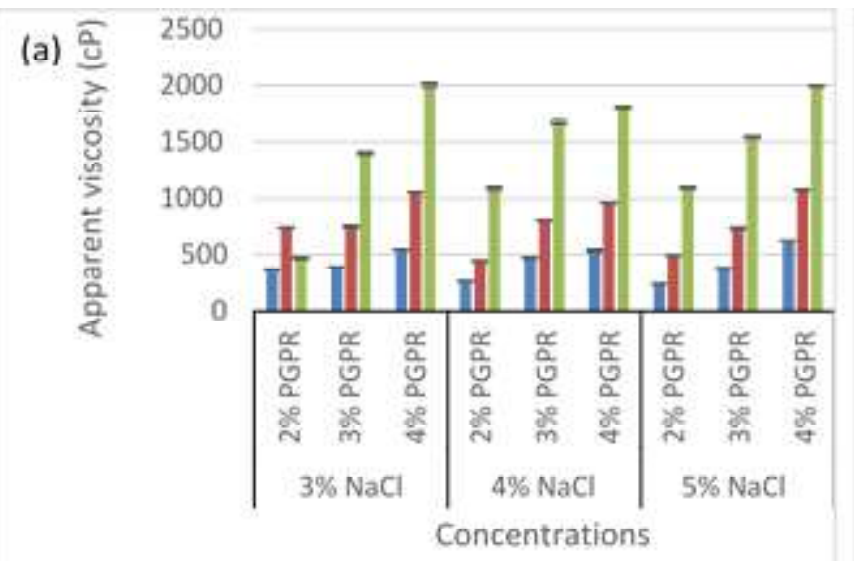

$=$ WPC-Pectin-1.5\% $=$ WPC-Pectin-3.0\% $=$ WPC-Pectin- $4.5 \%$

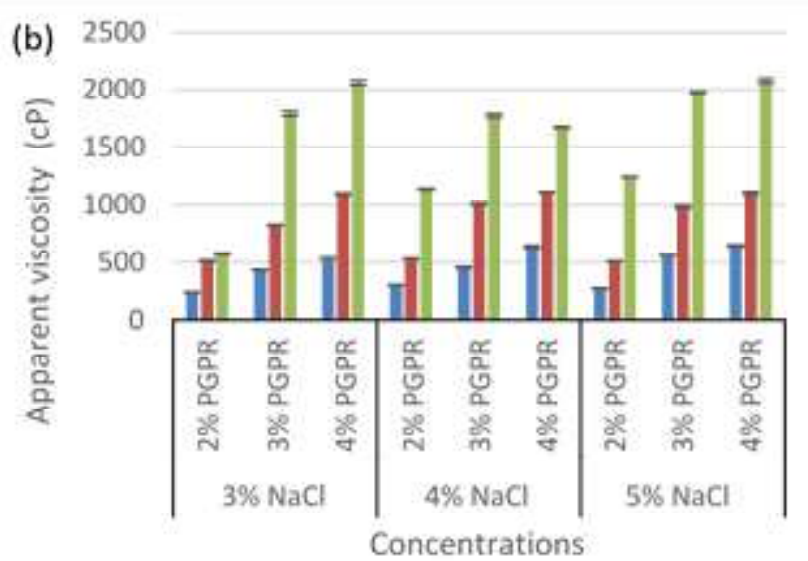

= SC-Pectin-1.5\% $\quad$ SC-Pectin-3.0\% $\equiv$ SC-Pectin- $4.5 \%$

Fig 1. Effect of $\mathrm{NaCl}, \mathrm{PGPR}$ and dairy protein-polysaccharide complexes (a): WPC-P, (b): SC-P on apparent viscosity of double emulsion; $\mathrm{n}=3$

Apparent viscosity of the primary emulsion $\left(\mathrm{W}_{1} / \mathrm{O}\right)$ increased with increasing PGPR concentration (Choudhary et al. 2018). Hence, the increased apparent viscosity of the final double emulsion $\left(\mathrm{W}_{1} / \mathrm{O} / \mathrm{W}_{2}\right)$ may be due to increased resistance to shearing during secondary emulsification. Our results were in agreement with studies reported by Su et al. (2006) and Bahtz et al. (2016), who found that the viscosity of the W/O emulsion increased with increasing concentrations of PGPR. This may have led to a subsequent reduction in the rate of coalescence and Ostwald ripening of the water droplets by decreasing the droplet diameter. On the other hand, though with initial increase in $\mathrm{NaCl}$ concentration, the apparent viscosity increased, it reduced at higher $\mathrm{NaCl}$ concentration. This may be because $\mathrm{NaCl}$ plays an important role in the formation of double emulsion by matching the osmotic and laplace pressure between the two aqueous phases $\left(\mathrm{W}_{1}\right.$ and $\left.\mathrm{W}_{2}\right)$ of the double emulsion. Presence of excess $\mathrm{NaCl}$ concentration in inner aqueous phase causes a migration of the water droplets from outer aqueous phase $\left(\mathrm{W}_{2}\right)$ to inner aqueous phase $\left(\mathrm{W}_{1}\right)$, leading to subsequent swelling and sometimes bursting of the $\mathrm{W}_{1} / \mathrm{O}$ droplets in the presence of concentration gradient between the two aqueous phases (Lutz and Garti, 2006; Rosano et al. 1998).

\section{Zeta potential}

The effect of the variables on $\zeta$-potential of the double emulsion is shown in Fig. $2(\mathrm{a}, \mathrm{b})$. The double emulsion stabilized with the WPC-P complex exhibited higher $\zeta$-potential than their SC-P stabilized counterparts. The mean $\zeta$-potential values increased with increase in concentration of SC-P complex (1.5-4.5\%), whereas it was found decreased with increase in concentration of WPC-P complex. The $\zeta$-potential values of both complexes (WPC-P and SC-P) stabilized double emulsion increased with increasing concentration of PGPR while it was found to decrease up to $4 \% \mathrm{NaCl}$ before increasing at $5 \% \mathrm{NaCl}$ concentration. All three variables and their interactions showed a very highly significant $(p<0.001)$ effect on $\zeta$-potential values of the double emulsion (Table 2).

According to Mirhosseini et al. (2008), an emulsion is considered as stable if the absolute zeta potential value is more than 25 . Hence, $\zeta$-potential is considered a key indicator for the stability of double emulsion $(\mathrm{W} / \mathrm{O} / \mathrm{W})$ because the stability is affected by surface charge $(\zeta$-potential) of the emulsion droplets. $\zeta$-potential values below 25 indicated flocculation, while those above $25 \mathrm{mV}$ indicated deflocculating emulsions (Mirhosseini et al. 2009). The negative surface charge of the double emulsion increased with increase in concentration of the complexes in the external aqueous phase $\left(\mathrm{W}_{2}\right)$ of the double emulsions $\left(\mathrm{W}_{1} / \mathrm{O} / \mathrm{W}_{2}\right)$. This effect can be attributed to the increase in electrostatic repulsion between the protein-polysaccharide complex molecules associated with their increased electrical charge, which prevented the aggregation and flocculation of the droplets. Our results are in good agreements with Guzey and McClements (2007), who reported that as the pectin concentration $(0-0.05 \%$, wt $\%)$ increased, the magnitude of zeta potential changed from positive to negative because the anionic pectin molecules adsorbed to the surface of cationic protein-coated droplets until the saturation of pectin concentration occurred. Further adsorption of the pectin may be prevented because the cationic binding sites get saturated with anionic groups of the pectin particles or due to the electrostatic repulsion between adsorbed and non-adsorbed pectin particles.

Prichapan and Klinkesorn (2014) reported that zeta potential was higher in $\mathrm{W}_{1} / \mathrm{O} / \mathrm{W}_{2}$ emulsions prepared with $\mathrm{SC}$ than those with WPC, and therefore, it had more electrostatic repulsive force between droplets, which prevents droplet flocculation and coalescence. In presence of high salt concentration, the magnitude of $\zeta$-potential decreased may be due to the screening effect of electrically charged ions. This meant that the counter- 


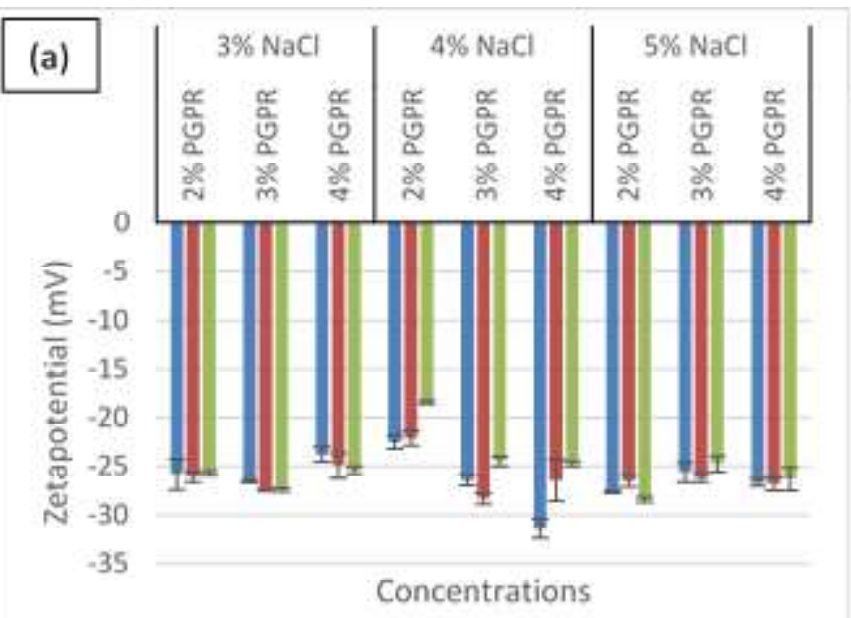

WPC-Pectin-1.5\% WPC-Pectin-3.0\% $=$ WPC-Pectin-4.5\%

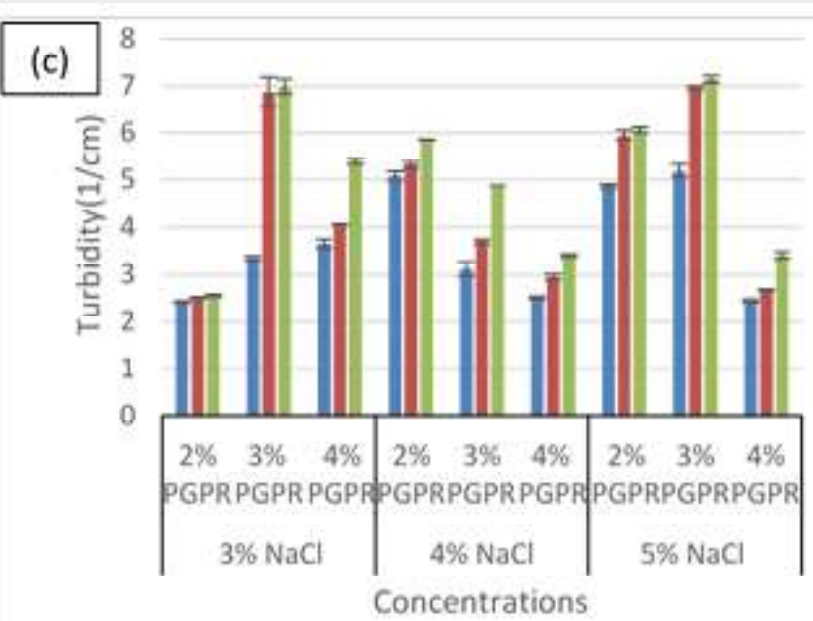

a WPC-Pectin-1.5\% | WPC-Pectin-3.0\% W WPC-Pectin-4.5\%

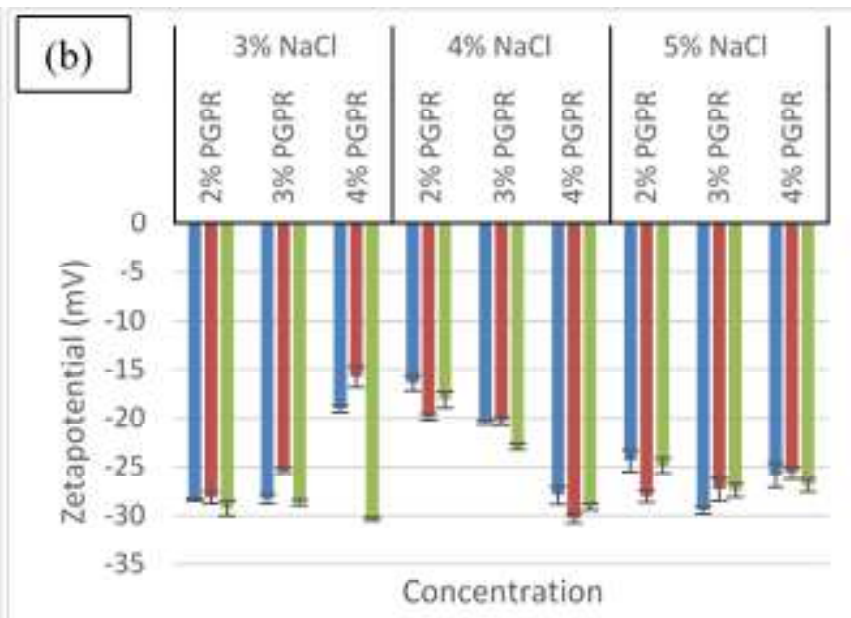

$=$ SC-Pectin-1.5\% $=$ SC-Pectin-3.0\% $=$ SC-Pectin-4.5\%

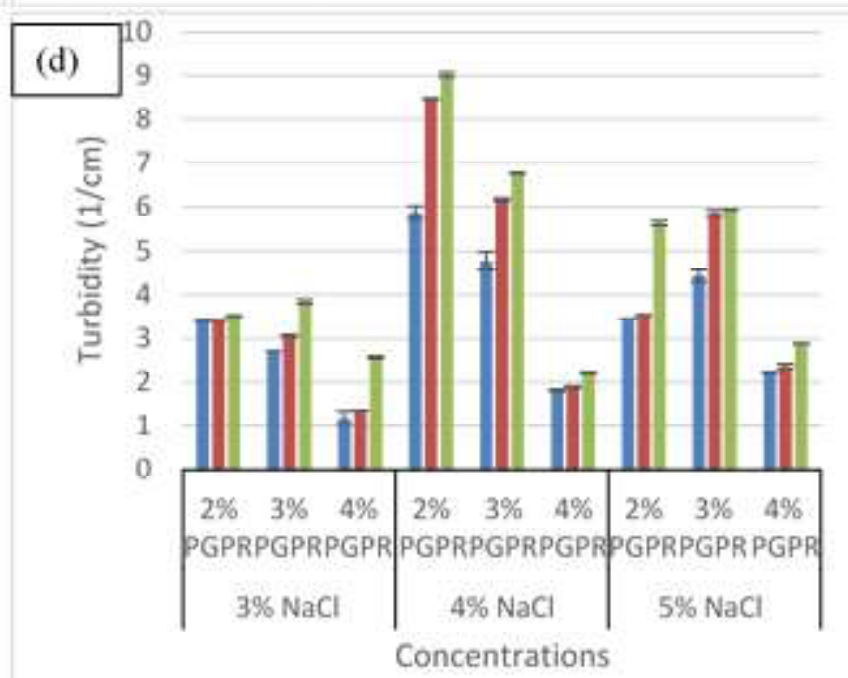

=SC-Pectin-1,5\% $=$ SC-Pectin-3.0\% $\equiv$ SC-Pectin- $4.5 \%$

Fig 2. Effect of NaCl, PGPR and dairy protein-polysaccharide complexes (a): WPC-P (b): SC-P on zeta potential and (c): WPC$\mathrm{P}(\mathrm{b})$ : SC-P on turbidity of double emulsion; $\mathrm{n}=3$

ions $\left(\mathrm{Na}^{+}\right)$in inner aqueous phase accumulated loosely around the negatively charged $-\mathrm{COO}^{-}$groups on the proteinpolysaccharide complex surface, due to the electrostatic interaction between the emulsion droplets and ion-binding effect. Low ionic (salt) concentration facilitated a strong electrostatic repulsion between the emulsion droplets, which prevents ions coming into close contact. However, once a critical ion (salt) concentration was reached, above this concentration electrostatic repulsion was no longer strong sufficient to overcome the attractive forces such as van der Wall and hydrophobic forces acting between the emulsion droplets, thus the emulsion droplets aggregate (McClements 2004). As a result of salt addition, the negative surface charge ( $\zeta$-potential) of the double emulsions shifted towards zero (slightly positive). This results supports the finding of Liu et al. (2012) and Onsaard et al. (2014) that the magnitude of the electrical charge ( $\zeta$-potential) of emulsions prepared with SC-carboxymethylcellulose and WPC-maltodextrin/ carrageenan was negative at all salt $(\mathrm{NaCl})$ concentrations studied $(0-500 \mathrm{mM})$, but the magnitude of surface charge decreased as well as the salt concentration increased due to reduction in the electrostatic repulsion between oil-water emulsion droplets. Lutz et al. (2009b) also found a lower $\zeta$-potential value $(-37 \pm 3 \mathrm{mV})$ of double emulsions stabilized with most negatively charged WPI/ U63 as compared to other pectin type WPI/C63 $(-28 \pm 3 \mathrm{mV})$. This negative surface charge prevented flocculation and coalescence by facilitating electrostatic repulsion between the emulsion droplets.

\section{Turbidity}




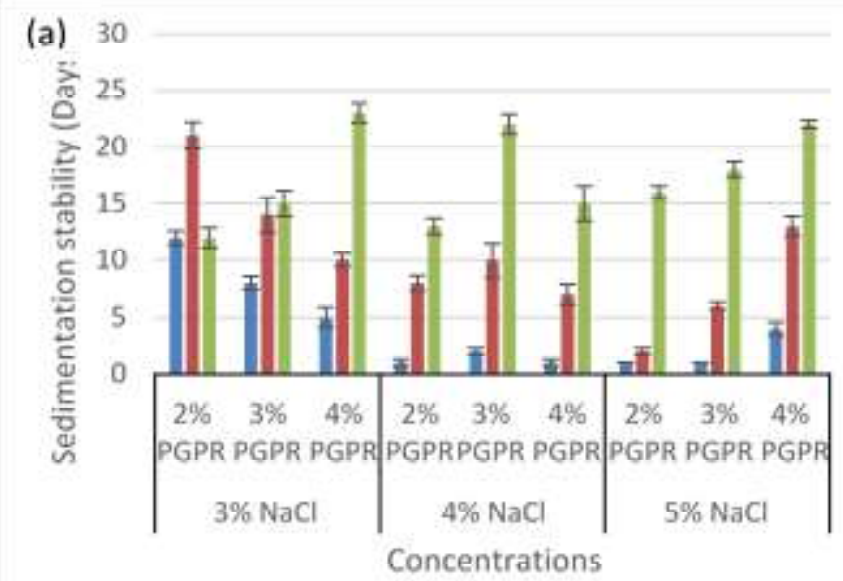

WPC-Pectin-1.5\% \# WPC-Pectin-3.0\% wWPC-Pectin-4.5\% (b) 35

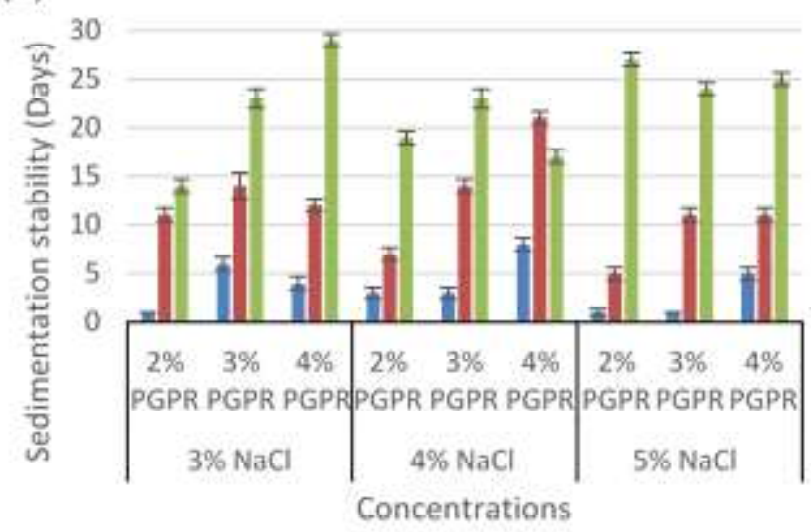

wSC.Pectin-1.5\% mSC-Pectin-3.0\% = SC-Pectin-4.5\%

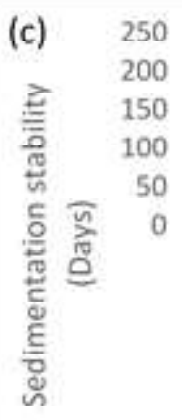

=WPC-Pectin-1.5\% =WPC-Pectin-3.0\% $=$ WPC-Pectin-4.5\%

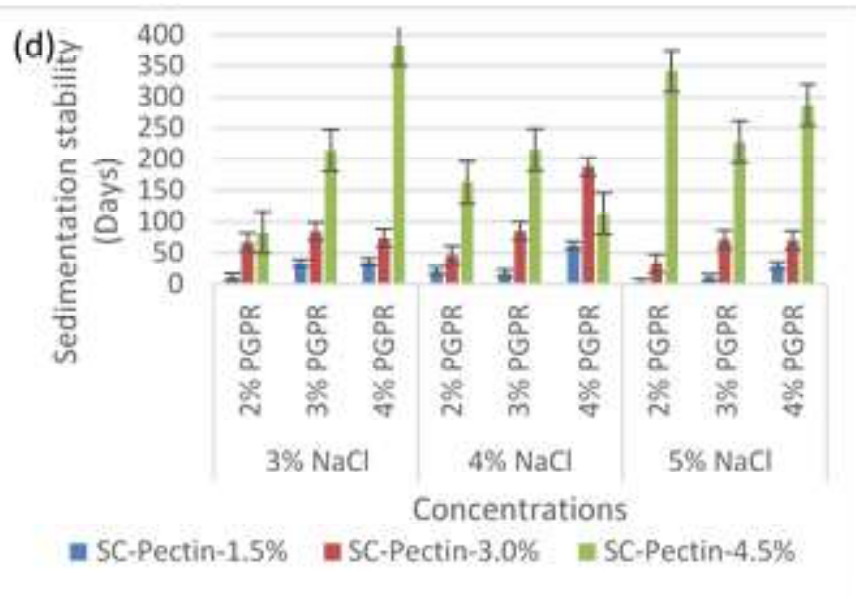

Fig 3. Effect of salt, PGPR and dairy protein-polysaccharide complexes (a): WPC-P (b): SC-P $\left(37^{\circ} \mathrm{C}\right)$ (c): WPC-P (d): SC-P $\left(7^{\circ} \mathrm{C}\right)$ on sedimentation stability of double emulsion; $n=3$

The effect of the variables on the turbidity of the double emulsion is shown in Fig. 2 (c,d). The average turbidity values were found lower in SC-P stabilized double emulsion than WPC-P stabilized samples and it increased with increasing concentration of both complexes (1.5-4.5\%). The range of turbidity values with the minimum and maximum concentration of the complex were as follow: $\mathrm{DE}_{\mathrm{SC}-\mathrm{P}}\left(2.95 \pm 0.22 \mathrm{~cm}^{-1}\right.$ to $\left.5.04 \pm 0.43 \mathrm{~cm}^{-1}\right)<\mathrm{DE}_{\mathrm{WPC}-\mathrm{P}}$ $\left(3.63 \pm 0.21 \mathrm{~cm}^{-1}\right.$ to $\left.4.94 \pm 0.34 \mathrm{~cm}^{-1}\right)$. The mean turbidity values of both complexes (SC-P and WPC-P) stabilized double emulsion increased up to $3 \%$ PGPR, after that it decreased at $4 \%$ PGPR concentration. The range of turbidity values with the minimum and maximum concentration of $\mathrm{NaCl}$ are as follow: $\mathrm{DE}_{\mathrm{SC}-\mathrm{P}}$ $\left(3.12 \pm 0.30 \mathrm{~cm}^{-1}\right.$ to $\left.4.04 \pm 0.27 \mathrm{~cm}^{-1}\right)<\mathrm{DE}_{\text {WPC-P }}\left(3.86 \pm 0.28 \mathrm{~cm}^{-1}\right.$ to $\left.4.97 \pm 0.33 \mathrm{~cm}^{-1}\right)$. There was very high significant $(\mathrm{p}<0.001)$ difference in the turbidity of double emulsions stabilized with each of the three variables i.e., $\mathrm{NaCl}$, PGPR and complexes (WPC$\mathrm{P}$ and SC-P). Their interaction also showed a very high significant $(p<0.001)$ effect on turbidity of the double emulsion (Table 2$)$.
Several factors were reported to influence the emulsifying properties of protein-polysaccharide complexes such as proteinto-polysaccharide molar mass ratio, their total concentration, polymer charge density, $\mathrm{pH}$, ionic strength, temperature and method of mixing (Benichou et al. 2002; Schmitt and Turgeon 2011). Ettelaie et al. (2005) reported that electrostatic proteinpolysaccharide complexes onto the surface of protein-coated oil droplets led to increased emulsion stability by a thick secondary layer of charged polysaccharide. This could be due to the electrostatic and steric interaction between the protein and charged polysaccharide molecules. It has been reflected that the chemically modified proteins via electrostatic and steric complexation with polysaccharide could enhance emulsifying properties, especially below their isoelectric $\mathrm{pH}$ and at low ionic (salt) concentrations by maintaining molecular integrity and altered solubility (Surh et al. 2006; Lutz et al. 2009b). Emulsion activity (EA) and emulsion stability (ES) of double emulsion can be enhanced by covering the emulsion droplets by surfactants. 
The biopolymers form a bulky and flexible film that may be strongly anchored on the O/W interface (Benichou et al. 2007; Lutz and Aserin 2007). Surh et al. (2006) associated the high viscosity of SC-emulsion with the addition of pectin at $\mathrm{pH} 3$ and 4, due to high degree of droplet flocculation caused by charge neutralization and bridging flocculation of oppositely charged SC-(+ve)-stabilized emulsion droplets and pectin (-ve) molecules. Double emulsions $\left(\mathrm{W}_{1} / \mathrm{O} / \mathrm{W}_{2}\right)$ exhibited higher optical turbidity with increasing concentration of the dairy protein-polysaccharide complexes, probably at higher concentration of the complexes led to high viscosity of the emulsion by inducing strong electrostatic interaction. Lutz et al. $(2009 \mathrm{a}, \mathrm{b})$ reported that WPImodified pectin soluble complexes had net negative zeta-potential at pHd"6.0 that enable the repulsive interaction (electrostatic and steric) between the droplet interface, which results in a stable emulsion. Su et al. (2008) reported that the ionic environment reduced the emulsifying ability of the hydrophobic emulsifier
(PGPR) from $4 \%(\mathrm{w} / \mathrm{w})$ PGPR in a buffered system to $2 \%(\mathrm{w} / \mathrm{w})$ PGPR in distilled water systems and with an encapsulation efficiency $>90 \%$ of $\mathrm{W} / \mathrm{O} / \mathrm{W}$ emulsions prepared with SUPER GUM $^{\mathrm{TM}}$

\section{Sedimentation stability}

The double emulsion samples were kept at $37 \pm 1^{\circ} \mathrm{C}$ and $7 \pm 1^{\circ} \mathrm{C}$ and observed daily for phase separation. It was observed that the sedimentation stability (by visual separation) is a function of storage temperature. Fig. 3 depicts the effect of variables such as $\mathrm{NaCl}, \mathrm{PGPR}$ and complexes (WPC-P and SC-P) on sedimentation stability. The double emulsions prepared with SC-P were stable for almost one month (29 days) and more than one year (383 days) while WPC-P stabilized emulsions were stable for 23 days and 229 days at $37^{\circ} \mathrm{C}$ and $7{ }^{\circ} \mathrm{C}$, respectively. It was found that as concentration of both complexes increased, sedimentation

Table 3 Analysis of variance of sedimentation stability of double emulsion stabilized with WPC/SC-P complex

\begin{tabular}{|c|c|c|c|c|c|}
\hline Temperature & Components & $\begin{array}{l}\text { Type III } \\
\text { Sum of } \\
\text { Squares }\end{array}$ & $\begin{array}{l}\text { Degree } \\
\text { of } \\
\text { freedom (Df) }\end{array}$ & $\begin{array}{l}\text { Mean } \\
\text { Square }\end{array}$ & F value \\
\hline$\overline{37^{\circ} \mathrm{C}}$ & $\mathrm{NaCl}$ & 27.938 & 2 & 13.969 & $11.203^{* * *}$ \\
\hline & PGPR & 405.975 & 2 & 202.988 & $162.792 * * *$ \\
\hline & Complex & 769.191 & 1 & 769.191 & $616.876^{* * *}$ \\
\hline & Level of Complexes & 7665.198 & 2 & 3832.599 & $3073.668 * * *$ \\
\hline & $\mathrm{NaCl}^{*}$ Level & 267.210 & 4 & 66.802 & $53.574 * * *$ \\
\hline & $\mathrm{NaCl}^{*}$ Complex & 54.531 & 2 & 27.265 & $21.866^{* * *}$ \\
\hline & Complex*Level & 606.309 & 2 & 303.154 & $243.124 * * *$ \\
\hline & Complex*PGPR & 35.901 & 2 & 17.951 & $14.396^{* * *}$ \\
\hline & Complex* $\mathrm{NaCl}^{*}$ Level & 334.025 & 4 & 83.506 & $66.970 * * *$ \\
\hline & Complex*NaCl*Level*PGPR & 99.679 & 8 & 12.460 & $9.993 * * *$ \\
\hline \multirow[t]{10}{*}{$7^{\circ} \mathrm{C}$} & $\mathrm{NaCl}$ & 12291.012 & 2 & 6145.506 & $10479.705 * * *$ \\
\hline & PGPR & 25711.272 & 2 & 12855.636 & $21922.242 * * *$ \\
\hline & Complex & 279000.469 & 1 & 27900.469 & $47577.642 * * *$ \\
\hline & Level of Complexes & 685042.123 & 2 & 342521.062 & $584088.547 * * *$ \\
\hline & PGPR $* \mathrm{NaCl}$ & 24835.877 & 4 & 6208.969 & $10587.926^{* * *}$ \\
\hline & Level*PGPR & 34540.210 & 4 & 8635.052 & $14725.037 * * *$ \\
\hline & $\mathrm{NaCl}^{*}$ Level & 44290.802 & 4 & 11072.701 & $18881.868 * * *$ \\
\hline & $\mathrm{NaCl} *$ Complex & 23422.864 & 2 & 11711.432 & $19971.074 * * *$ \\
\hline & Complex*Level & 66340.198 & 2 & 33170.099 & $56563.747 * * *$ \\
\hline & Complex*PGPR & 13283.864 & 2 & 6641.932 & $11326.242^{* * *}$ \\
\hline
\end{tabular}


stability increased. The sedimentation stability was found to increase with increase in PGPR (2-4\%) concentration in both SC$\mathrm{P}$ and WPC-P complex stabilized double emulsion, It could be seen from Fig. 3 $(\mathrm{a}, \mathrm{c})$ that sedimentation stability was highest at $3 \% \mathrm{NaCl}$, followed by $5 \%$ and $4 \% \mathrm{NaCl}$ at $37^{\circ} \mathrm{C}$ and it was found to decrease with increase in salt concentration $(3-5 \%)$ at $7{ }^{\circ} \mathrm{C}$. Whereas Fig. 3(b,d) shows that it was highest at $4 \% \mathrm{NaCl}$, followed by $3 \%$ and $5 \% \mathrm{NaCl}$ at $37^{\circ} \mathrm{C}$ and, it increased with increase in $\mathrm{NaCl}$ concentration $(3-5 \%)$ at $7{ }^{\circ} \mathrm{C}$.

It is evident from Table 3 that the sedimentation stability (by visual observation) of double emulsion was very highly significantly affected by the variables such as $\mathrm{NaCl}$, PGPR, WPC$\mathrm{P}$ and SC-P complexes and their interaction.

Lutz et al. (2009a) observed no coalescence in double emulsions stabilized with soluble WPI/modified pectin complex for almost one month, because oil droplets were fully covered by external oil-water interfacial $\left(\mathrm{O} / \mathrm{W}_{2}\right)$ film comprising of the WPI/modified pectin. The soluble complexes of WPI/pectin also reduced the interfacial tension on surface of the emulsion droplets. Further they reported that the level of creaming also depended on the $\mathrm{NaCl}$ concentration $(1.0,1.5$ and $4.4 \%, \mathrm{w} / \mathrm{w})$ in the inner aqueous phase. Salminen and Weiss (2014) studied the electrostatic adsorption of heat-treated biopolymer complexes [Whey protein isolate (WPI)-apple pectin at $85^{\circ} \mathrm{C}$ for $20 \mathrm{~min}$ ] and stability of these complexes on emulsion interfaces. They found that the emulsions covered with the complexes showed good stability to salt (up to $200 \mathrm{mM}$ ) and heat (up to $90^{\circ} \mathrm{C}$ ) by creating a thick polymer layer. Muschiolik et al. (2006) investigated the effect of addition of salt $(\mathrm{NaCl})$ in inner aqueous phase of multiple emulsions prepared with 4\% PGPR during storage. They found that presence of the salt in the inner aqueous phase $\left(\mathrm{W}_{1}\right)$ of multiple emulsions is essential to carry out coalescence free W/ $\mathrm{O}$ emulsions prepared with PGPR, an addition of salt increased the encapsulation stability and oil droplet stability of multiple emulsions. Actually, salt is considered to be a co-stabilizer, a lipophobic that builds-up the osmotic pressure to counterbalance the Laplace pressure, and consequently stabilizes emulsions against diffusional degradation known as Ostwald ripening (Landfester 2006; Capek 2010; Colman et al. 2014). Bahtz et al. (2016) reported that PGPR, when used as an oil-soluble surfactant, was able to spontaneously form tiny water droplets in oil phase that cause structural changes in the oil layer. Further, they described that the overall water transport rate increases and water transport stagnates because of maximized structure formation at below and above a critical concentration of the oil-soluble surfactant, respectively.

\section{Conclusions}

An attempt was made to fabricate a stable water-in-oil-in-water $\left(\mathrm{W}_{1} / \mathrm{O} / \mathrm{W}_{2}\right)$ double emulsion encapsulating bitter gourd extract, using a two-step emulsification technique. The results of the present study indicated that several factors such as $\mathrm{NaCl}$, PGPR and protein-polysaccharide complexes (WPC-P and SC-P) and their interaction exhibited a synergistic effect on the stability of the fabricated double emulsion. The deciding attributes (turbidity, zeta-potential, apparent viscosity and sedimentation stability) were very highly dependent on the all the variables such as $\mathrm{NaCl}$, PGPR and complex and their levels. SC-P stabilized double emulsions were found more stable than WPC-P stabilized samples.

\section{References}

Bahtz J, Gunes DZ, Syrbe A, Mosca N, Fischer P, Windhab EJ (2016) Quantification of spontaneous W/O emulsification and its impact on the swelling kinetics of multiple $\mathrm{W} / \mathrm{O} / \mathrm{W}$ emulsions. Langmuir 32: $5787-5795$

Benichou A, Aserin A, Garti N (2002) Protein-polysaccharide interaction for stabilization of food emulsions. J Disper Sci Tech 23(1-3): 93123

Benichou A, Aserin A, Lutz R, Garti N (2007) Formation and characterization of amphiphilic conjugates of whey protein isolate (WPI)/xanthan to improve surface activity. Food Hydrocoll 21: 379-91

Capek I (2010) On inverse miniemulsion polymerization of conventional water-soluble monomers. Adv Colloid Interface Sci 156: 35

Choudhary U, Sabikhi L, Abdul Hussain S, Khamrui K, Sharma V, Vij S (2018) Stabilizing the primary emulsion with hydrophobic emulsifiers and salt for encapsulating herbal extracts in a double emulsion. $\mathrm{J}$ Food Process Preserv 42:e13699 https://doi.org/10.1111/jfpp.13699

Colmán MME, Chicoma DL, Giudici R, Araújo PHH, Sayer C (2014) Acrylamide inverse miniemulsion polymerization in situ, real-time monitoring using spectroscopy. Braz J Chem Eng 31(4):925

Ettelaie R, Dickinson E, Murray BS (2005) Self-consistent-field studies of mediated steric interactions in mixed protein + polysaccharide solutions. Food colloids: interaction, microstructure and processing 74-84

Guzey D, McClements DJ (2007) Impact of electrostatic interactions on formation and stability of emulsions containing oil droplets coated by $\beta$-lactoglobulin-pectin complexes. J Agrc Food Chem 55: 475485

Habicht SD, Kind V, Rudloff S, Borsch C, Mueller AS, Pallauf J, Yang R, Krawinkel MB (2011) Quantification of antidiabetic extracts and compounds in bitter gourd varieties. Food Chem 126: 172-176

Hernández-Marín NY, Lobato-Calleros C, Vernon-Carter EJ (2013) Stability and rheology of water-in-oil-in-water multiple emulsions made with protein-polysaccharide soluble complexes. J Food Eng 119: $181-187$

Jiménez-Colmenero F (2013) Potential applications of multiple emulsions in the development of healthy and functional foods. Food Res Int 52: $64-74$

Klein M, Aserin A, Ishai PB, Garti N (2013) Interactions between whey proteins isolate and gum Arabic. Colloids Surf B 79:377-383

Kumar SM, Sabikhi L, Lamba H (2020) Emulsification properties of sodium caseinate-based conjugates with selected polysaccharides. Int J Dairy Tech.

Landfester K (2006) Synthesis of colloidal particles in miniemulsions. Annu Rev Mater Res 36: 231

Li B, Jiang Y, Liu F, Chai Z, Li Y, Li Y, Leng X (2012) Synergistic effects of whey protein-polysaccharide complexes on the controlled release of lipid-soluble and water-soluble vitamins in $\mathrm{W}_{1} / \mathrm{O} / \mathrm{W}_{2}$ double emulsion systems. Int J Food Sci Technol 47: 248-254 
Liu L, Zhao Q, Liu T, Kong J, Long Z, Zhao M (2012) Sodium caseinate/ carboxymethylcellulose interactions at oil-water interface: relationship to emulsion stability. Food Chem 132: 1822-1829

Lupi FR, Gabriele D, de Cindio B, Sánchez MC, Gallegos C (2011) A rheological analysis of structured water-in-olive oil emulsions. J Food Eng 107: 296-303

Lutz R, Aserin A (2007) Multiple Emulsions: Technology and Applications, John Wiley \& Sons, Inc., Hoboken, NJ, USA, pp. 85

Lutz R, Aserin A, Wicker L, Garti N (2009a) Double emulsions stabilized by a charged complex of modiûed pectin and whey protein isolate. Colloids Surf B 72: 121-127

Lutz R, Aserin A, Wicker L, Garti N (2009b) Release of electrolytes from W/O/W double emulsions stabilized by a soluble complex of modiûed pectin and whey protein isolate. Colloids Surf B 74: 178-185

Lutz R, Garti N (2006) Double emulsions. In P. Somasundaran (Ed.), Encyclopedia of surface and colloids science (pp. 1816-1845). London: Taylor \& Francis.

McClements DJ (2004) Protein-stabilized emulsions. Curr Opin Colloid Interface Sci 9: 305-313

Mirhosseini H, Tan CP, Hamid NSA, Yusof S (2008) Effect of Arabic gum, xanthan gum and orange oil contents on $\zeta$-potential, conductivity, stability, size index and $\mathrm{pH}$ of orange beverage emulsion. Colloids Surf A Physicochem Eng Asp 315: 47-56

Mirhosseini H, Tan CP, Taherian AR, Boo HC (2009) Modeling the physicochemical properties of orange beverage emulsion as function of main emulsion components using response surface methodology. Carbohyd Polym 75:512-520

Muschiolik G, Scherze I, Preissler P, Weiss J, Knoth A, Fechner A (2006) Multiple emulsions - preparation and stability. IUFoST 123-137 doi: 10.1051/IUFoST:20060043.

Onsaard E, Putthanimon J, Singthong J, Thammarutwasik P (2014) Influence of maltodextrin and environmental stresses on stability of whey protein concentrate/ k-carrageenan stabilized sesame oilin-water emulsions. Revista de ATA 20: 614-628

Oppermann AKL, Piqueras-Fiszman B, de Graaf C, Scholten E, Stieger M (2016) Descriptive sensory profiling of double emulsions with gelled and non-gelled inner water phase. Food Res Int 85:215-23

Pawlik AK, Cox PW, Norton IT (2010) Food grade duplex emulsions designed and stabilized with different osmotic pressure. J Colloid Interface Sci 352: 59-67

Pawlik AK, Norton IT (2014) Bridging benchtop research and industrial processed foods: structuring of model food emulsions. Food Struc 1: 24-38

Pearce KN, Kinsella JE (1978) Emulsifying Properties of Proteins: Evaluation of a Turbidimetric Technique. J Agrc Food Chem 26: 716-723
Prichapan N, Klinkesorn U (2014) Effect of emulsifiers on properties and stability of water-in-rice bran oil-in-water $(\mathrm{W} / \mathrm{O} / \mathrm{W})$ emulsions. $18^{\text {th }}$ World Congress on Clinical Nutrition (WCCN)

Rosano HL, Gandolfo FG, Hidrot JDP (1998) Stability of W/O/W multiple emulsions influence of ripening and interfacial interactions. Colloids Surf A Physicochem Eng Asp 138: 109-121.

Salminen H, Weiss J (2014) Electrostatic adsorption and stability of whey protein-pectin complexes on emulsion interfaces. Food Hydrocoll 35: $410-419$

Sameh H, Wafa E, Sihem B, Fernando LC (2012) Influence of diffusive transport on the structural evolution of $\mathrm{W} / \mathrm{O} / \mathrm{W}$ emulsions. Langmuir 28: $17597-17608$

Sapei L, Naqvi MA, Rousseau D (2012) Stability and release properties of double emulsions for food applications. Food Hydrocoll 27:316323

Schmitt C, Turgeon SL (2011) Protein/polysaccharide complexes and coacervates in food systems. Adv Colloid Interface Sci 167: 63-70

Shima M, Tanaka M, Kimura Y, Adachi S, Matsuno R (2004) Hydrolysis of the oil phase of a $\mathrm{W} / \mathrm{O} / \mathrm{W}$ emulsion by pancreatic lipase. J Controlled Release 94: 53-61

Su J, Flanagan J, Hemar Y, Singh H (2006) Synergistic effects of polyglycerol ester of polyricinoleic acid and sodium caseinate on the stabilization of water-oil-water emulsions. Food Hydrocoll 20: 261-268

Su J, Flanagan J, Singh H (2008) Improving encapsulation efûciency and stability of water-in-oil-in-water emulsions using a modiûed gum arabic (Acacia (sen) SUPER GUM ${ }^{(\mathrm{TM})}$. Food Hydrocoll 22: 112-120

Surh J, Decker EA, McClements DJ (2006) Influence of pH and pectin type on properties and stability of sodium-caseinate stabilized oilin-water emulsions. Food Hydrocoll 20: 607-618

Surh J, Vladisavljević GT, Mun S, McClements DJ (2007) Preparation and characterization of water/oil and water/oil/water emulsions containing biopolymer-gelled water droplets. J Agrc Food Chem 55: 175-84

Wu S, Ng L (2008) Antioxidant and free radical scavenging activities of wild bitter melon (Momordica charantia Linn. var. abbreviata Ser.) in Taiwan. LWT 41: 323-330 